\title{
Faceted crack initiation characteristics for high-cycle and very-high-cycle fatigue of a titanium alloy under different stress ratios
}

\author{
Xiaolong Liu, Chengqi Sun, Youshi Hong* \\ LNM, Institute of Mechanics, Chinese Academy of Sciences, Beijing 100190, China
}

\section{A R T I C L E I N F O}

\section{Article history:}

Received 18 December 2015

Received in revised form 23 February 2016

Accepted 7 March 2016

Available online 11 March 2016

\section{Keywords}

Ti-6Al-4V alloy

Faceted crack initiation

Very-high-cycle fatigue

Stress ratio

Cluster of primary $\alpha$ grains

\begin{abstract}
A B S T R A C T
Ultrasonic fatigue tests were conducted at the stress ratios of $-1,-0.5,-0.1,0.1$ and 0.5 for a Ti-6Al-4V alloy in high-cycle and very-high-cycle fatigue regimes. Experimental results showed that faceted crack initiation was the main failure mode for specimens at the stress ratios of $-0.1,0.1$ and 0.5 , and multi-site faceted crack initiation was observed at the stress ratios of 0.1 and 0.5 . The measurements indicated that the number of facets increased with the increase of stress ratio. Based on the observations, the mechanism of faceted crack initiation was proposed, i.e., (i) cleavage of isolated primary $\alpha$ grains in cluster; (ii) gradual growth of originated cracks (facets), and the coalescence of adjacent facets; and (iii) coalesced facets forming a main crack in the cluster. Moreover, a model based on Poisson defect distribution is proposed to describe the effects of stress ratio on faceted crack initiation, which is in agreement with the experimental results.
\end{abstract}

(c) 2016 Elsevier Ltd. All rights reserved.

\section{Introduction}

Very-high-cycle fatigue (VHCF) behavior of metallic materials has been drawing increased attention because many engineering components such as high-speed train axles, turbine blade and automobile cylinders require $10^{8}$ or even more loading cycles of safe performance [1-5]. Titanium alloys are widely used as structural materials in aircraft engineering due to their high strengthto-weight ratio, corrosion resistance and high-temperature resistance [6,7]. Recently, faceted crack initiation was observed in high-cycle fatigue (HCF) and VHCF regimes of titanium alloys, which resulted in the sharp decrease of fatigue strength [8]. Two types of fatigue fracture surface for faceted crack initiation, i.e. surface-with-facets (crack initiation from the surface of specimen with subsurface facets) and interior-with-facets (crack initiation from the interior of specimen with facets) were reported in HCF and VHCF regimes of a Ti-6Al-4V alloys, and no pre-existed defects were observed in the crack initiation region [9]. The faceted morphology was in relation with the cleavage of primary $\alpha$ grains [10], and the groups of primary $\alpha$ grains that formed facets were regarded as the clusters of primary $\alpha$ grains [11]. For a titanium alloy that is free of defects (inclusions and micro-voids), the facets in the cluster are crack initiation origins. Moreover, the clusters of primary $\alpha$ grains in the specimen have significant effects on the

\footnotetext{
* Corresponding author. Tel.: +86 1082543966.

E-mail address: hongys@imech.ac.cn (Y. Hong).
}

failure types of titanium alloys in HCF and VHCF regimes [12]. Therefore, facets and clusters are the major concerns in the investigation of faceted crack initiation.

The mechanism of crack initiation is crucial in the HCF and VHCF regimes since more than $90 \%$ of the fatigue life is consumed in the crack initiation stage [13-15]. Thus, the mechanism of faceted crack initiation is an important topic in the HCF and VHCF regimes of titanium alloys. The faceted crack initiation consists of two processes, the formation of facets and the facets developing into a main crack. For the formation of facets, Neal and Blenkinsop [10] proposed that the restricted operative slip systems and dislocation pile-ups at grain boundaries aggravated stress concentration, which became high enough to induce the cleavage on the plane $\langle 10 \overline{1} 7\rangle$. Chan et al. $[16,17]$ analyzed the deformation behavior of titanium alloys with primary $\alpha$ grains and lamellar $\alpha_{s}+\beta$ colonies by applying finite-element method (FEM), and indicated that the softer phase tended to concentrate both the plastic strain and the hydrostatic stress for reaching yielding first and leading to interior crack initiation. Chai et al. $[18,19]$ obtained similar results by investigating the mechanism of subsurface non-defect fatigue crack origins (SNDFCO).

Some researchers also indicated that the state of stress ratio $(R)$ was of importance for the faceted crack initiation [20]. For example, Zuo et al. [21] and Takeuchi et al. [22-24] found the faceted crack initiation in the HCF and VHCF regimes of Ti-6Al-4V alloy for $R=-1$. While in the results by Morrissey et al. [25,26], no facet was found for the similar microstructure of Ti-6Al-4V alloy. For 


$\begin{array}{ll}\text { Nomenclature } \\ \sigma_{\mathrm{a}} & \text { applied stress amplitude } \\ N_{\mathrm{f}} & \text { fatigue life } \\ R & \text { stress ratio } \\ f & \text { probability density of grains for which cleavage occurs } \\ F & \text { cumulative probability of grains for which cleavage oc- } \\ & \text { curs } \\ \sigma_{\mathrm{max}} & \text { applied maximum stress } \\ \sigma_{\mathrm{c}, \mathrm{m}} & \text { mean value of cleavage strength }\end{array}$

$d \quad$ related variance

$N \quad$ number of grains that may cleave

$A \quad$ area of the section bearing fatigue loading

$P(N=0) \quad$ occurrence probability of no faceted crack initiation

$P(N=1) \quad$ occurrence probability of single-site faceted crack initiation

$P(N \geqslant 2)$ occurrence probability of multi-site faceted crack initiation the case of positive stress ratios, crack initiation sites with facets were observed at fracture surfaces for Ti-6Al-4V alloy [27-29]. This suggested that the increase of stress ratio promoted the occurrence of faceted crack initiation. However, the quantitative analysis of stress ratio on facet formation in the faceted crack initiation site was rarely reported. In addition, there are just few reports on the formation process of faceted crack initiation [e.g. 30].

The competition mechanism between surface and subsurface crack initiation is another important aspect in the HCF and VHCF regimes of titanium alloys, which causes the scatter of fatigue life $[31,32]$. Chandran [12] proposed that cluster-defects prevail in a $\mathrm{Ti}-10 \mathrm{~V}-2 \mathrm{Fe}-3 \mathrm{Al}$ alloy, and these clusters of primary $\alpha$ grains are responsible for the faceted crack initiation. The occurrence of surface crack initiation or interior crack initiation is determined by the competition among the clusters located at surface rim area and interior area of specimen for being the crack initiation site. Normally, only one crack initiation site was observed for the faceted crack initiation. The multi-site faceted crack initiation including surface and subsurface faceted crack initiation is rarely investigated. The occurrence of multi-site faceted crack initiation suggests the existence of competition relation between surface and subsurface faceted crack initiation [33]. Moreover, the observation of microstructure in the clusters may give more information for the competition process among these clusters. Bantounas et al. [3436] investigated the role of microtexture on faceted crack initiation of a Ti-6Al-4V alloy. In their results, local texture with grains of favorable orientation was found beneath crack initiation site, which was supposed to be responsible for the faceted crack initiation. This result was supported by Bridier et al. [37] and Biavant et al. [38]. However, the observations by Szczepanski et al. [30] revealed that there was no evident difference in the microstructure between the faceted crack initiation region and the ductile fracture region. The competition relation between surface and interior faceted crack initiation needs further investigation.

In this paper, the mechanism of faceted crack initiation in HCF and VHCF regimes of a Ti-6Al-4V alloy was investigated. First, ultrasonic fatigue tests were performed on the tested $\mathrm{Ti}-6 \mathrm{Al}-4 \mathrm{~V}$ alloy at $R=-1,-0.5,-0.1,0.1$ and 0.5 . The faceted crack initiation was observed for the cases of $R=-0.1,0.1$ and 0.5 , and typically the multi-site faceted crack initiation prevailed in the cases of $R=0.1$ and 0.5 . Then, back scattering electron (BSE) examination and orientation imaging microscopy (OIM) diffraction were conducted on profile samples beneath the fracture surface of the specimens at $R=0.1$ and 0.5 . Based on the observations of cracks initiation and early growth stage, the process of faceted crack initiation was revealed and the related mechanism was proposed. The effects of stress ratio on the faceted crack initiation were therefore discussed.

\section{Test material and experimental methods}

\subsection{Test material}

The material used in this investigation is an $\alpha-\beta$ titanium alloy (Ti-6Al-4V). The chemical compositions (wt\%) are $5.8 \mathrm{Al}, 4.2 \mathrm{~V}$, $0.12 \mathrm{Fe}, 0.03 \mathrm{~N}, 0.02 \mathrm{C}, 0.005 \mathrm{H}, 0.15 \mathrm{O}$ and balance Ti. Typical heat treatment was performed to produce bimodal microstructures. The resulted microstructure fraction and the related mechanical properties are listed in Table 1, for which the tensile tests were conducted on five cylindrical specimens with the diameter of $6 \mathrm{~mm}$ and the microhardness was obtained by the average of twenty indentation points for each of three specimens.

\subsection{Fatigue testing and fractography observation}

Fatigue testing was conducted with an ultrasonic fatigue test machine (GF-20k from Lusar Corporation) at a resonance frequency of $20 \mathrm{kHz}$ at room temperature in air. The ultrasonic fatigue machine was equipped in a conventional tensile machine (capacity $20 \mathrm{kN}$ ) to enable the ultrasonic cycling under an amount of mean stress. Compressive air was used to cool the specimen during ultrasonic fatigue testing. Fig. 1 presents the shape and dimensions of the specimen (just one end of the specimen with screw for $R=-1$ case). The cyclic stress was loaded by the ultrasonic fatigue machine, and a value of mean stress was superimposed by the connected tensile machine. The fracture surfaces were observed by a field-emission type scanning electron microscope (SEM).

For the observation of microstructure and cracks beneath fracture surface, the fracture surface was sectioned by an ion beam cross section polisher. Fig. 2 is the schematic of profile sample preparation for OIM and BSE analyses. The part of the sample outside the shield plate was eliminated and the desired cross section was obtained, so that the possibly existing micro-cracks and the microstructure underneath the fracture surface can be clearly examined. An AZTEC device from Oxford Instruments was used to conduct the OIM examination of the cross section and a Hellos Nanolab 600i device was used to perform the BSE analysis.

Table 1

Microstructure and mechanical properties of the test material.

\begin{tabular}{|c|c|c|c|c|c|}
\hline Alloy & Primary $\alpha$ grains (Vol.\%) & Lamellar colonies (Vol.\%) & Yield strength (MPa) & Tensile strength (MPa) & Microhardness HV $\left(\mathrm{kgf} / \mathrm{mm}^{2}\right)$ \\
\hline Ti-6Al-4V & $50 \%$ & $50 \%$ & 812 & 945 & 310 \\
\hline
\end{tabular}




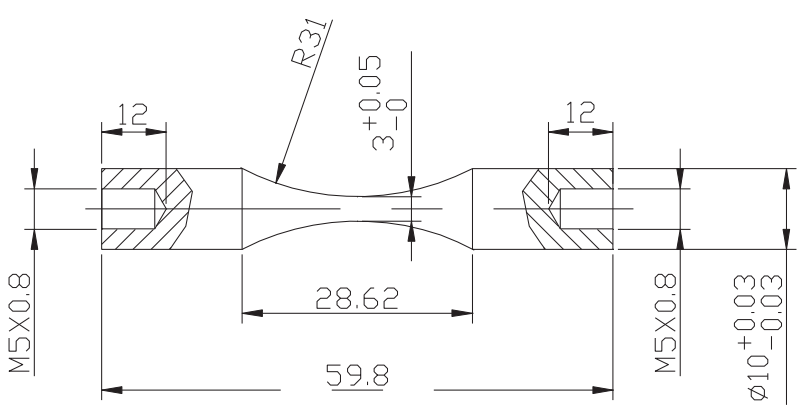

Fig. 1. Shape and dimensions (in $\mathrm{mm}$ ) of fatigue testing specimen.

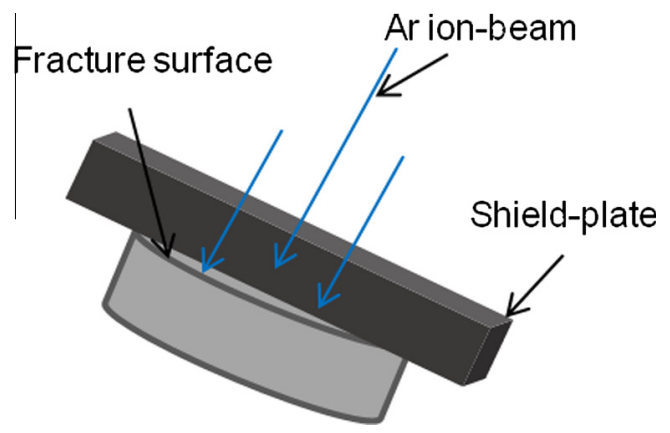

Fig. 2. Schematic of profile sample prepared by ion beam cross section polisher.

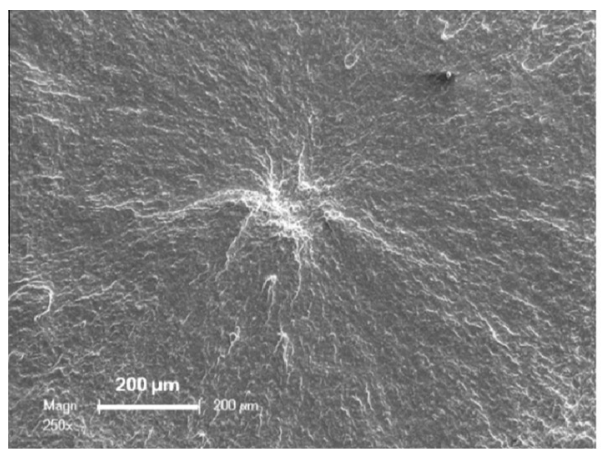

(a)
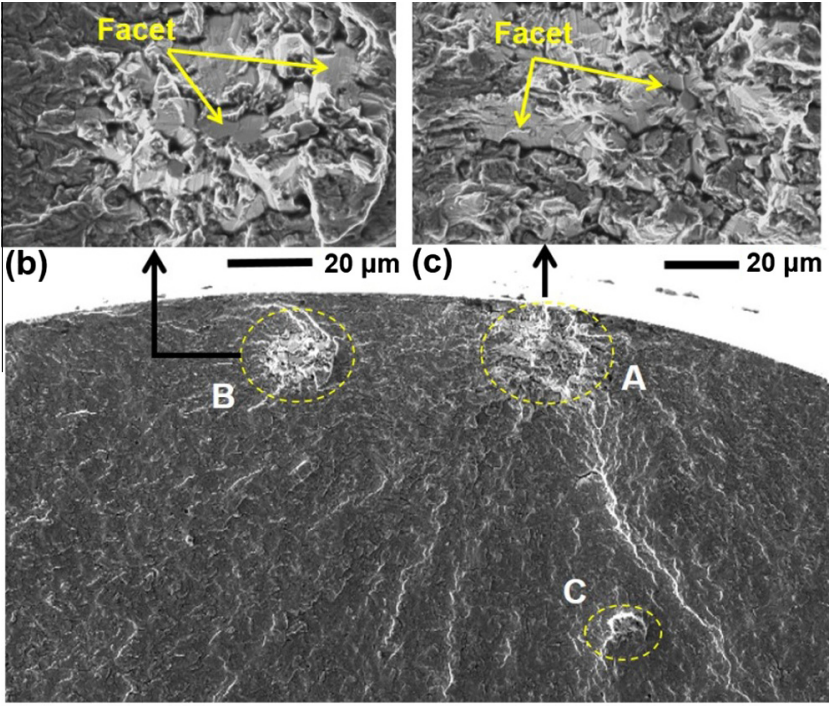

(a)

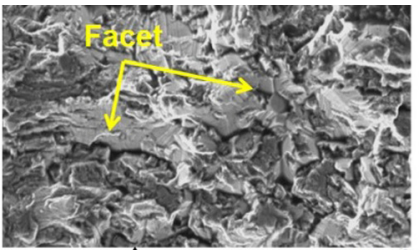

(c)

$100 \mu \mathrm{m}$
Fig. 5. SEM images $\left(R=0.1, \sigma_{\mathrm{a}}=367 \mathrm{MPa}, N_{\mathrm{f}}=9.14 \times 10^{6}\right)$. (a) Fracture surface of multi-site faceted crack initiation, (b) enlargement of crack initiation site B, and (c) enlargement of crack initiation site A.

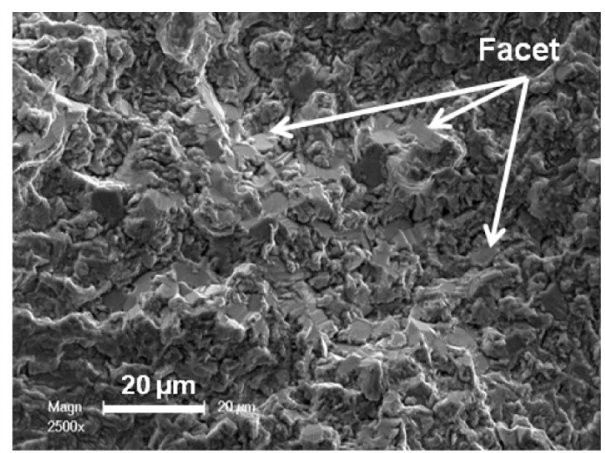

(b)

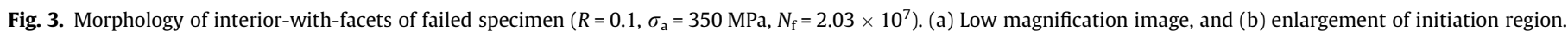

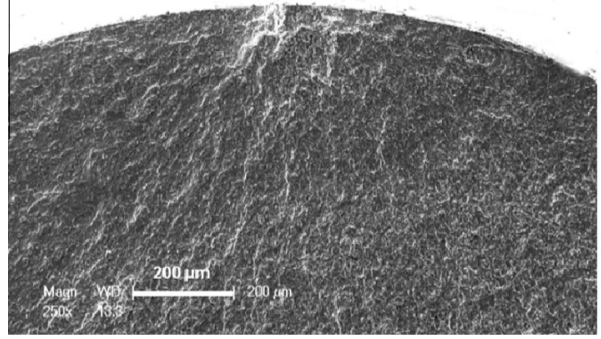

(a)

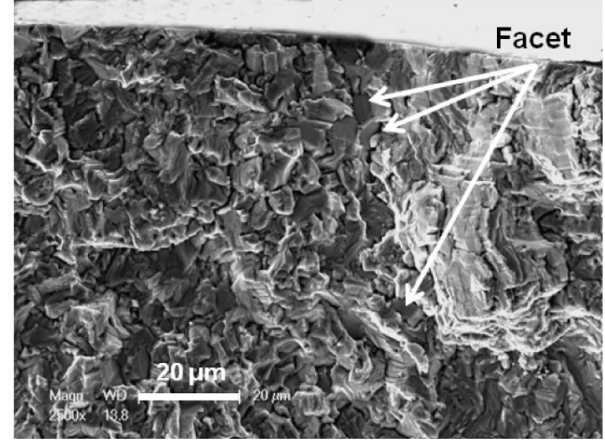

(b)

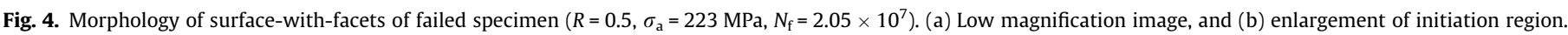




\section{Experimental results}

Figs. 3 and 4 show the typical morphology of interior-withfacets and surface-with-facets of failed specimens. It is seen from Figs. $3 \mathrm{~b}$ and $4 \mathrm{~b}$ that, for both interior-with-facets and surfacewith-facets, several facets were presented in a single faceted crack initiation site. The morphology of crack initiation and early growth for the failure type of interior-with-facets is rough fracture surface as shown in Fig. 3, which is called rough area.

Multi-site faceted crack initiation was observed in the cases of $R=0.1$ and 0.5 , as shown in Fig. 5. It is seen that the formation of facets in the clusters (i.e., the groups of primary $\alpha$ grains that formed facets [39]) with regard to crack initiation sites A, B and C (Fig. 5) is likely to occur independently from one to another, for which cluster A became the main crack initiation site. The coexistence of surface and interior faceted crack initiation is the result of the competition for being the main crack initiation site among the clusters.

Table 2 lists the occurrence percentage of no faceted crack initiation, single-site faceted crack initiation and multi-site faceted crack initiation at different stress ratios. It is seen from Table 2 that the number of crack initiation site is related to applied stress ratio. Multi-site faceted crack initiation occurs only at high stress ratios ( 0.1 and 0.5 ), and the occurrence proportion of multi-site faceted crack initiation increases with the increasing of stress ratio.

Fig. 6 shows the $\mathrm{S}-\mathrm{N}$ data of specimens at $R=-1,-0.5,-0.1,0.1$ and 0.5 . As commonly used in the S-N data demonstration, the piecewise linear expression was plotted to show the data trend of a group with the same stress ratio. It is seen that, with the increase of stress ratio, the tested stress range in terms of stress amplitude decreases and the tested stress range in terms of the maximum stress increases. A sharp decrease in fatigue strength happened in HCF and VHCF regimes in relation to faceted crack initiation. This implies that the faceted crack initiation has a substantial effect on the HCF and VHCF behavior of titanium alloys.

\section{Discussion}

\subsection{Quantitative evaluation of facets}

Fig. 7 presents the number of facets in the rough area as a function of fatigue life for the failure type of interior-with-facets at different stress ratios. It is seen that the number of facets in the crack initiation region is independent of fatigue life, but is related to the stress ratio. With the increase of stress ratio, i.e. the increase of the maximum stress, the number of facets tends to increase. This indicates that the increase of stress ratio promotes the occurrence of the cleavage of primary $\alpha$ grains. The average size of facets is about $4.9 \mu \mathrm{m}$ which was measured from the SEM micrographs for a total of 12 specimens ( 4 at $R=-0.1,4$ at $R=0.1$ and 4 at $R=0.5$ ), while the primary $\alpha$ grain size is about $5.9 \mu \mathrm{m}$ [8]. The distribution of facet size is overlaid on the primary $\alpha$ grain size as shown in Fig. 8. The similar result was also reported in Ti-6246 [30].

For a further investigation on the spatial distribution of facets in the rough area, the interior crack initiation sites are treated as concentric penny cracks as shown in Fig. 9. Then Fig. 10 presents the fraction of facets as a function of the radius of penny cracks, in which the fraction of facets is the ratio of the number of facets in the penny crack to the total number of facets in rough area. The distribution of facets in rough area is relatively uniform, which implies that the probability for facet formation in different localized spots keeps nearly equality in the crack initiation region. Moreover, the distribution of facets seems independent of the maximum stress and fatigue life.

\subsection{Mechanism of faceted crack initiation}

The observation of facets in the crack initiation and early propagation stage is a direct way to reveal the mechanism of faceted crack initiation for titanium alloys in HCF and VHCF regimes. However, there is no such result reported so far. Here, special experiments were conducted to catch the appearance of the facets in the crack initiation and early propagation stage. The distribution of the stress in the specimen decreases gradually from the middle section of the specimen to the both ends of gauge length (Fig. 1). This implies that, in addition to the fracture surface of the specimen, the facets in the initiation and early propagation stage may exist at the cross-sections close to the fracture surface. Here, the fracture surface of specimen at $R=0.5$ was chosen for the profile observation because it contains the highest density of facets (Fig. 7). The fracture surface was sectioned along the dash line as shown in Fig. 11a and the method of sample preparation was shown in Fig. 2.

A zig-zag crack about $30 \mu \mathrm{m}$ in total length was found away from the fracture surface (Fig. 11b). It is seen that, Facet 1 and Facet 2 marked in Fig. 11c have not coalesced completely (white dashed ellipse in Fig. 11c). This suggests that the facets form first in the early stage of crack initiation and then coalesce. This evidence also confirms that the formation of facets is due to the cleavage of primary $\alpha$ grains.

Based on the result of Fig. 11c, the mechanism of faceted crack initiation was proposed as shown in Fig. 12: (i) a few primary $\alpha$ grains in the cluster of the specimen cleave independently under cyclic loading (Fig. 12b); (ii) the facet cracks grow gradually, and some of adjacent cracks coalesce (Fig. 12c); and (iii) the coalesced facets form a main crack in the cluster (Fig. 12d), which leads to final fracture.

\subsection{Multi-site faceted crack initiation}

Multi-site faceted crack initiation in HCF and VHCF regimes of titanium alloys is rarely reported in literature. For the case of steels, it is reported that more than one fish-eye formed from inclusions in the VHCF regime for a $\mathrm{Cr}-\mathrm{Ni}-\mathrm{W}$ steel, and the fisheyes were in a competition for becoming a main crack during fatigue cycling [33]. In our investigation, multi-site faceted crack initiation of titanium alloys was found for the first time, which indicates that there are many clusters that are possible to form cracks in the specimen. Consequently, the profile area beneath the fracture surface of specimen with multi-site crack initiation

Table 2

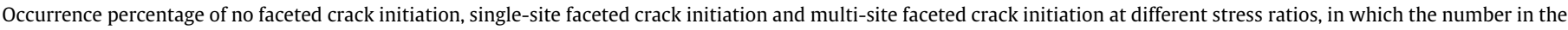
brackets denotes the number of specimens.

\begin{tabular}{|c|c|c|c|c|c|}
\hline & $R=-1$ & $R=-0.5$ & $R=-0.1$ & $R=0.1$ & $R=0.5$ \\
\hline I & $100 \%(10 / 10)$ & $100 \%(6 / 6)$ & $36.4 \%(4 / 11)$ & $0 \%(0 / 19)$ & $0 \%(0 / 18)$ \\
\hline II & $0 \%(0 / 10)$ & $0 \%(0 / 6)$ & $63.6 \%(7 / 11)$ & $84.3 \%(16 / 19)$ & $66.7 \%(12 / 18$ \\
\hline III & $0(0 / 10)$ & $0(0 / 6)$ & $0 \%(0 / 11)$ & $15.7 \%(3 / 19)$ & $33.3 \%(6 / 18)$ \\
\hline
\end{tabular}

Note: I: No faceted crack initiation, II: Single-site faceted crack initiation, III: Multi-site faceted crack initiation. 


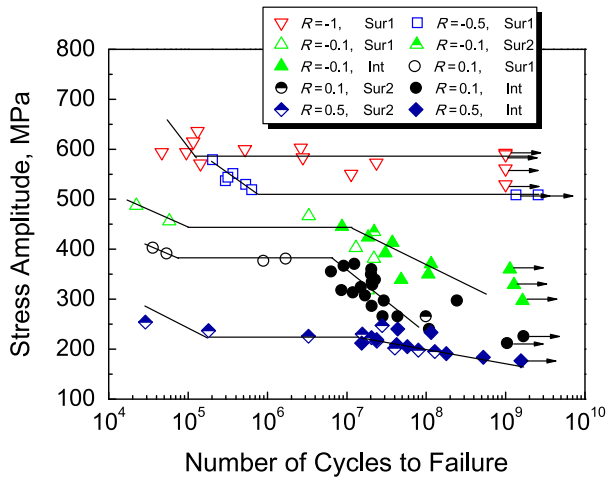

(a)

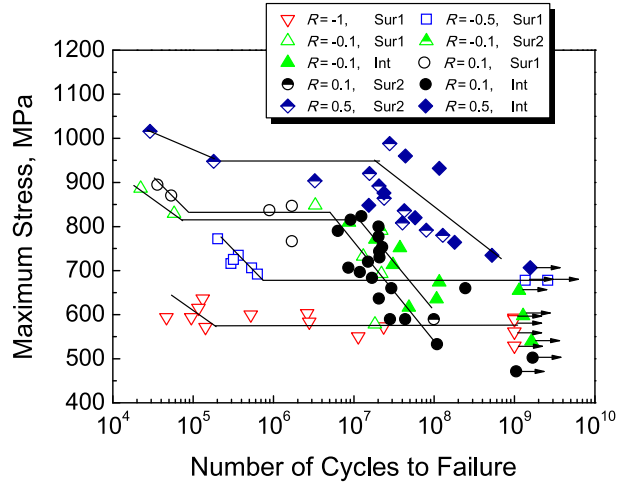

(b)

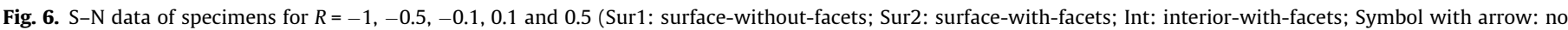
broken). (a) In terms of stress amplitude, and (b) in terms of the maximum stress.

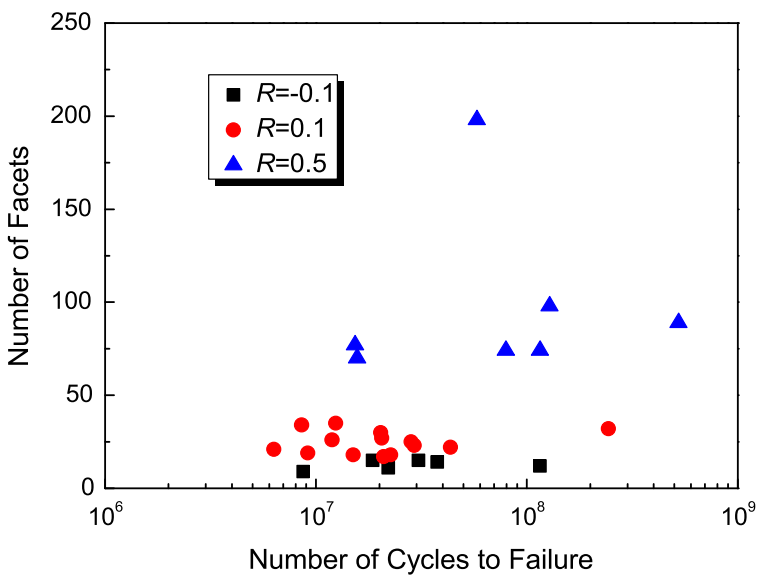

Fig. 7. Number of facets in crack initiation region versus fatigue life for different stress ratios.

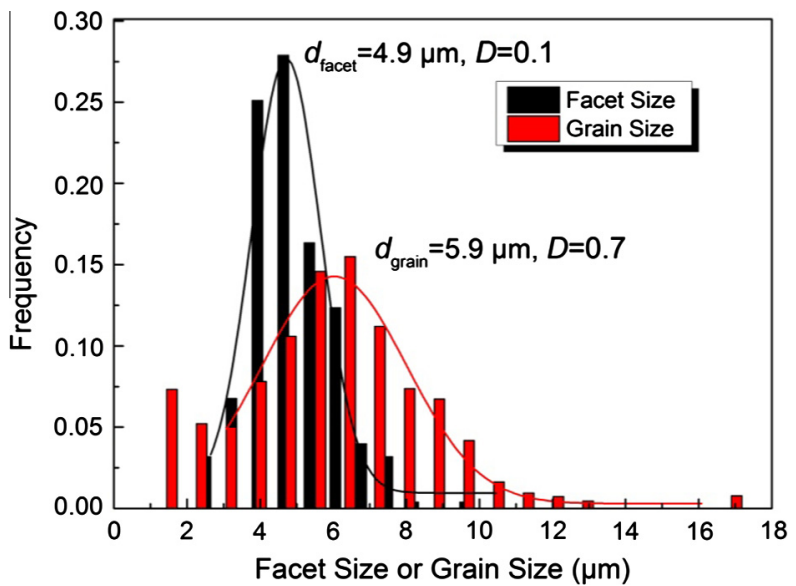

Fig. 8. Distribution of facet size $d_{\text {facet }}$ and primary $\alpha$ grain size $d_{\text {grain }}(D$ : variance).

was observed to show the microstructure in relation to different clusters of primary $\alpha$ grains. The fracture surface of the specimen was sectioned by ion beam cross section polisher along the dash line PQ as shown in Fig. 13a, and the OIM image of the crosssection is shown in Fig. 13b. It is noted that the microstructure feature including the grain size, the volume fraction of primary $\alpha$ grains and the crystallographic orientation for sites A and $B$ have

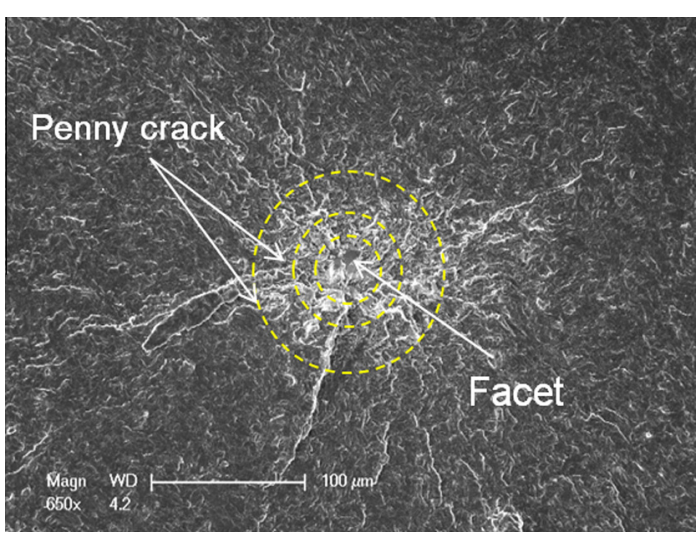

Fig. 9. Illustration of interior crack initiation site treated as a penny crack.

no obvious difference. This suggests that both clusters of primary $\alpha$ grains have the similar potential to be the crack initiation site. Further, there is also no evident microstructure difference between crack initiation site and ductile fracture region.

For titanium alloys, free of inclusions and pores, primary $\alpha$ grains have the potential to form cracks, which is substantially affected by the location of primary $\alpha$ grains and loading condition. The experimental results in Table 2 indicate that the related stress ratio plays an important role in the occurrence proportion of no faceted crack initiation, single-site faceted crack initiation and multi-site faceted crack initiation. Here, we discuss the effects of stress ratio and cluster location on the competition for being a main crack initiation site among clusters.

Our model [8] as well as that by Chandran et al. [39,40] took advantage of the Poisson defect distribution as shown in Eq. (1) to describe the competition among the clusters:

$P(n)=\frac{e^{-N}(N)^{n}}{n !}$

where $N$ is the number of total random clusters, and $n$ is the number of clusters that form cracks. Poisson defect distribution is the description of many clusters in a specimen, which have the potential to form cracks. Here, the experimental result of Fig. 13 supports the rationality that Poisson defect distribution is capable of describing the occurrence probabilities of defects in titanium alloys.

The occurrence probabilities of no faceted crack initiation, single-site faceted crack initiation and multi-site faceted crack initiation in relation to the total clusters $N$ are given by: 


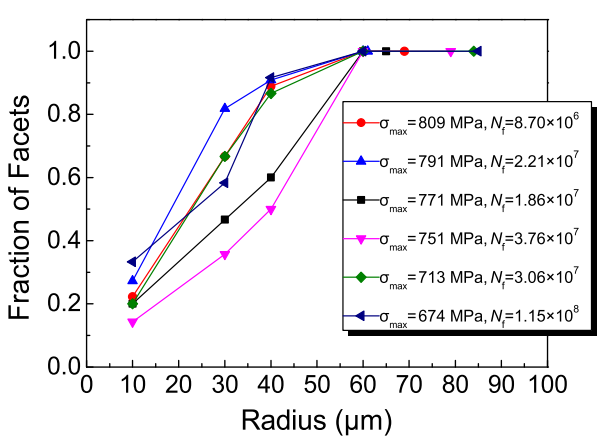

(a)

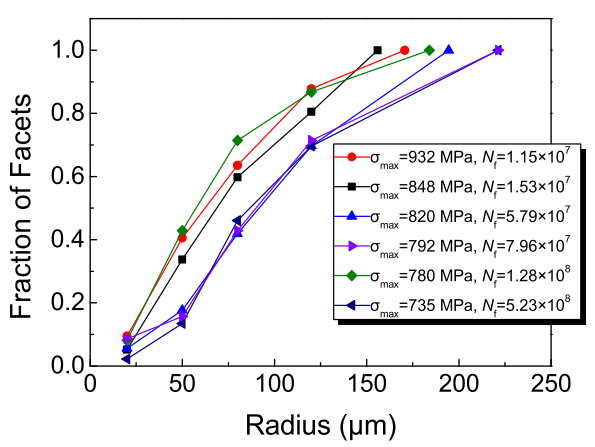

(b)

Fig. 10. Fraction of facets for crack initiation site at different stress ratios. (a) $R=-0.1$, and (b) $R=0.5$.

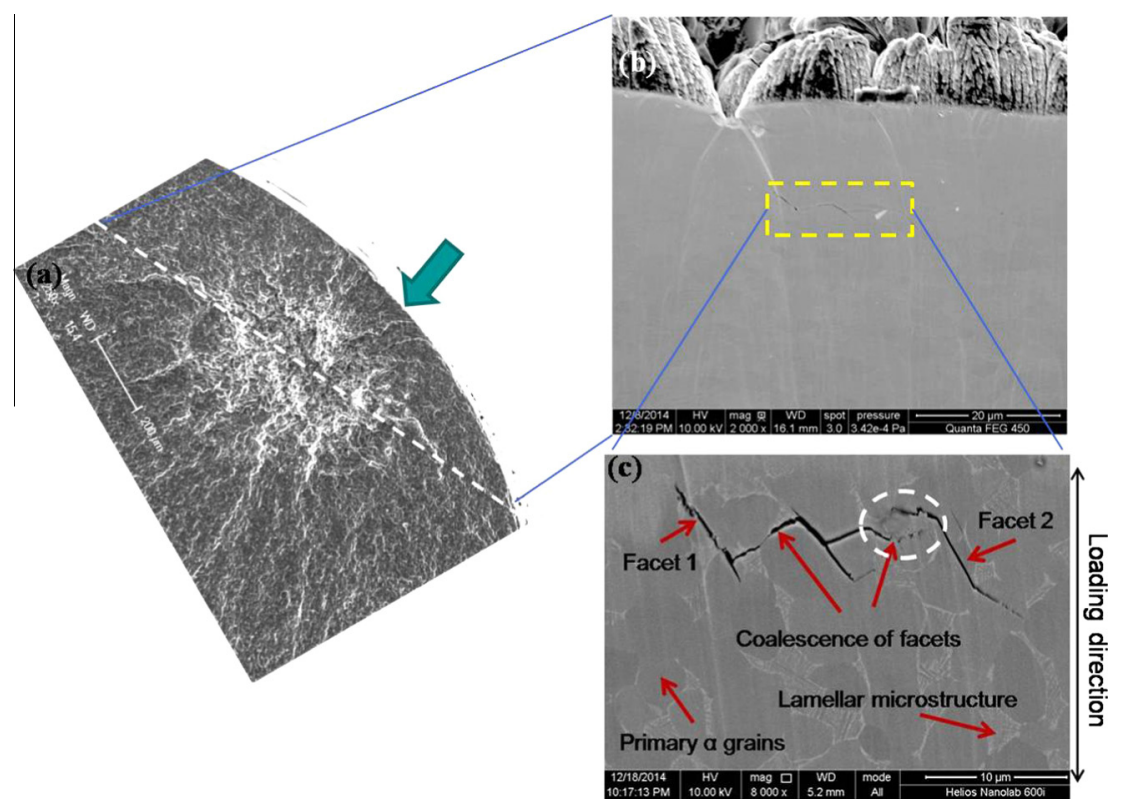

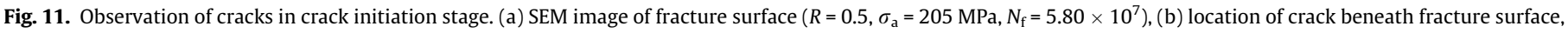
and (c) enlargement (BSE image) of crack beneath fracture surface.

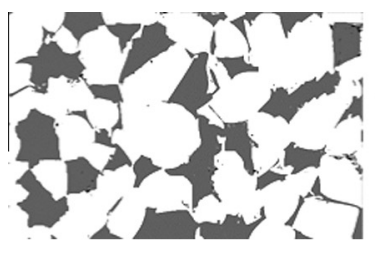

(a)

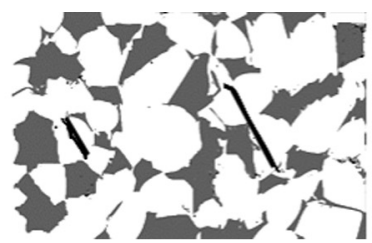

(b)

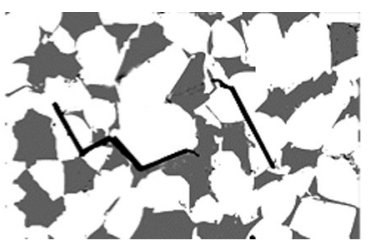

(c)

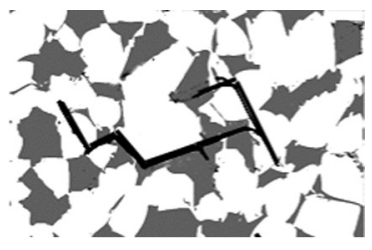

(d)

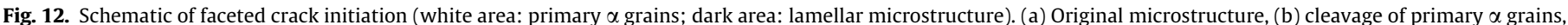
(c) coalescence of facets, and (d) formation of a main crack.

$$
\begin{aligned}
& P(n=0)=e^{-N} \\
& P(n=1)=N e^{-N} \\
& P(n \geqslant 2)=1-(1+N) e^{-N}
\end{aligned}
$$

Fatigue strength and fatigue life of materials are statistical and governed by defect distribution and specimen control volume [14], and the cleavage strength of each grain is not the same. The probability density of grains for which cleavage occurs, $f$, follows the classical Gaussian distribution as the following equation [41]. $f=\frac{1}{\sqrt{2 \pi} d} e^{-\frac{\left(\sigma_{\max }-\sigma_{\mathrm{c}, \mathrm{m}}\right)^{2}}{2 d^{2}}}$

where $\sigma_{\max }$ is the applied maximum stress, $\sigma_{\mathrm{c}, \mathrm{m}}$ is the mean value of the cleavage strength, and $d$ is the related variance.

The cumulative probability of grains for which cleavage occurs, $F$, is calculated by the integration of Eq. (5). Denote the area of the section bearing the fatigue loading as $A$, and the grain area of the material as $a$. Thus the number of grains that may cleave is:

$N=F A / a$ 


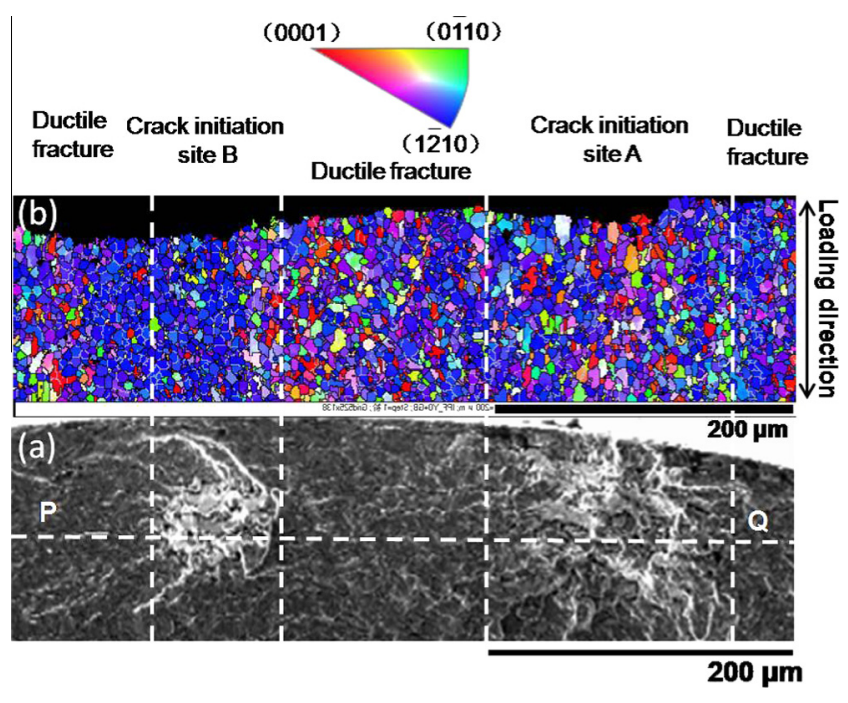

Fig. 13. (a) SEM image of crack initiation sites A and B, and (b) OIM image of crosssection along dashed line $\mathrm{PQ}$.

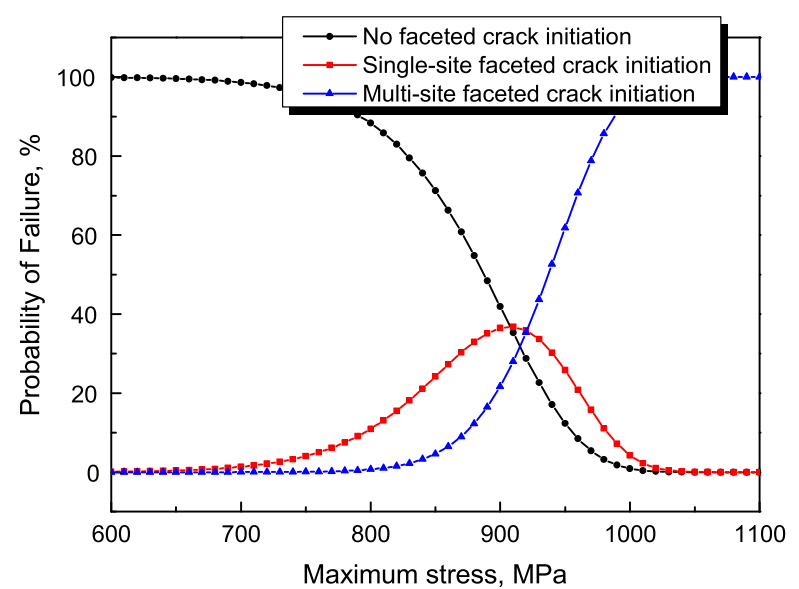

Fig. 14. Calculated probabilities for three failure types as a function of the maximum stress.

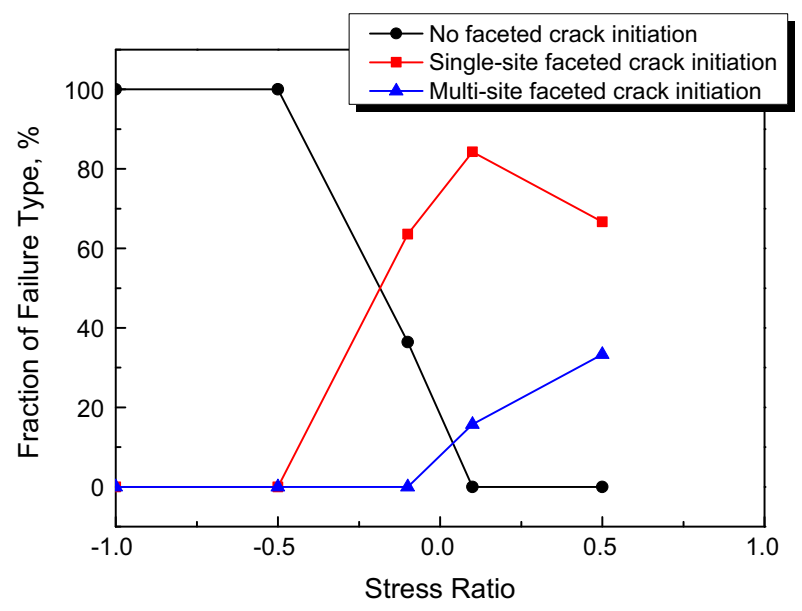

Fig. 15. Experimental results showing fraction of failure type as a function of stress ratio.
By substituting Eq. (6) into Eqs. (2)-(4), the occurrence probabilities of no faceted crack initiation, single-site faceted crack initiation and multi-site faceted crack initiation in relation to the maximum stress are obtained and presented in Fig. 14. The experimental results about the fraction of failure types in relation to the stress ratio are presented in Fig. 15. Although the abscissa in Figs. 14 and 15 is not the same, the maximum stress is in accordance with the increase of stress ratio as shown in Fig. 6. Thus, the tendency of the three failure types predicted by the model is in agreement with the experimental results shown in Fig. 15, i.e., the number of crack initiation sites increases with the increase of the related stress ratio.

For low stress ratio conditions ( -1 and -0.5$)$, no primary $\alpha$ grains in the cluster cleave, which results in no faceted crack initiation, i.e. surface crack initiation without facet [8]. For medium stress ratio conditions ( -0.1 and 0.1$)$, a small number of primary $\alpha$ grains in clusters cleave as shown in Fig. 7 , which results in only a few clusters in the minimum section to form cracks. This is the reason why single-site faceted crack initiation dominates the fatigue failure at the stress ratios of -0.1 and 0.1 . However, for high stress ratio of 0.5 , the cleavage of primary $\alpha$ grains in clusters is more prevalent as shown in Fig. 7, which results in more clusters developing into cracks. Therefore, multi-site faceted crack initiation becomes more common as listed in Table 2 .

Notch effects and size effects are also important topics in the investigation of HCF and VHCF of titanium alloys [42,43]. For specimens with notches, the failure type of no faceted crack initiation will be dominant for the surface notches decrease the threshold value of no faceted crack initiation, which will restrain the other two failure types of faceted crack initiation. The model in this paper aims to predict the case that specimens are free of surface notches and is not applicable for the case with notches. As shown in Eq. (6), with the increase of $A$, i.e., the increase of specimen size, the number of grains $(N)$ that may cleave increases. Then, the occurrence probability of no faceted crack initiation decreases as shown in Eq. (2), and the probabilities for single-site and multisite faceted crack initiation increase as shown in Eqs. (3) and (4). Indeed, notch effects and size effects on faceted crack initiation need further detailed investigations.

\section{Conclusions}

In this paper, the behavior and the mechanism of faceted crack initiation for the HCF and VHCF behavior of a Ti-6Al-4V alloy were experimentally investigated. The following conclusions are drawn.

(1) Faceted crack initiation (surface-with-facets and interiorwith-facets) dominates the failure mode in HCF and VHCF regimes of the Ti-6Al-4V alloy. No faceted crack initiation occurred mainly at low stress ratios ( -1 and -0.5$)$, singlesite faceted crack initiation occurred mainly at medium stress ratios $(-0.1$ and 0.1$)$, and the fracture surface often presents multi-site faceted crack initiation at high stress ratio (0.5). The number of faceted crack initiation site increased with the increase of stress ratio.

(2) Observations of zig-zag cracks beneath the fracture surface indicate that facets form first in the early stage of crack initiation and then coalesce. Based on this result, the mechanism of faceted crack initiation was proposed, i.e., (i) cleavage of isolated primary $\alpha$ grains in its cluster under cyclic loading; (ii) gradual growth of originated cracks (facets), and some of adjacent cracks coalesce; and (iii) the coalesced facets forming a main crack in the cluster, and leading to final failure.

(3) The multi-site faceted crack initiation implies the existence of competitive relation among clusters for being a crack initiation site. A model based on Poisson defect distribution is 
proposed to describe the effect of stress ratio on the occurrence probabilities of no faceted crack initiation, single-site faceted crack initiation and multi-site faceted crack initiation, which is in agreement with the experimental results.

\section{Acknowledgements}

The financial supports by the National Basic Research Program of China (2012CB937500) and by the National Natural Science Foundation of China (11572325 and 11202210) are gratefully appreciated.

\section{References}

[1] Fitzka M, Mayer H, Schuller R, Stanzl-Tschegg SE, Przeorski T, Krug P. Variable amplitude loading of spray-formed hypereutectic aluminium silicon alloy DISPAL (R) S232 in the VHCF regime. Fatigue Fract Eng Mater Struct 2014;37:945-57.

[2] Mayer H. Recent developments in ultrasonic fatigue. Fatigue Fract Eng Mater Struct 2016;39:3-29.

[3] Pang JC, Li SX, Zhang ZF. High-cycle fatigue and fracture behaviours of Cu-Be alloy with a wide strength range. Fatigue Fract Eng Mater Struct 2013;36:168-76.

[4] Paolino DS, Chiandussi G, Rossetto M. A unified statistical model for S-N fatigue curves: probabilistic definition. Fatigue Fract Eng Mater Struct 2013;36:187-201.

[5] Shanyavskiy AA. Very-high-cycle-fatigue of in-service air-engine blades, compressor and turbine. Sci China-Phys Mech Astron 2014;57:19-29.

[6] Walker KF, Newman JC. Improved test method and analytical modelling for fatigue crack growth in coarse-grain titanium alloy with rough fatigue surfaces. Fatigue Fract Eng Mater Struct 2014;37:659-70.

[7] Williams JC, Starke EA. Progress in structural materials for aerospace systems 11 the golden jubilee issue-selected topics in materials science and engineering: past, present and future. Acta Mater 2003;51:5775-99.

[8] Liu X, Sun C, Hong Y. Effects of stress ratio on high-cycle and very-high-cycle fatigue behavior of a Ti-6Al-4V alloy. Mater Sci Eng A 2015;622:228-35.

[9] Jha SK, Szczepanski CJ, Golden PJ, Porter WJ, John R. Characterization of fatigue crack-initiation facets in relation to lifetime variability in Ti-6Al-4V. Int J Fatigue 2012;42:248-57.

[10] Neal FD, Blenkinsop PA. Internal fatigue origins in $\alpha-\beta$ titanium allols. Acta Metall 1976;24:59-63.

[11] Jha SK, Chandran KSR. An unusual fatigue phenomenon: duality of the S-N fatigue curve in the $\beta$-titanium alloy Ti-10V-2Fe-3Al. Scripta Mater 2003;48:1207-12.

[12] Chandran KSR. Duality of fatigue failures of materials caused by Poisson defect statistics of competing failure modes. Nat Mater 2005;4:303-8.

[13] Hong Y, Lei Z, Sun C, Zhao A. Propensities of crack interior initiation and early growth for very-high-cycle fatigue of high strength steels. Int J Fatigue 2014;58:144-51.

[14] Lei Z, Xie J, Sun C, Hong Y. Effects of loading condition on very-high-cycle fatigue behaviour and dominant variable analysis. Sci China-Phys Mech Astron 2014;57:74-82.

[15] Marines-Garcia I, Paris PC, Tada H, Bathias C. Fatigue crack growth from small to long cracks in very-high-cycle fatigue with surface and internal "fish-eye" failures for ferrite-perlitic low carbon steel SAE 8620. Mater Sci Eng A 2007;468-470:120-8.

[16] Chan KS. Roles of microstructure in fatigue crack initiation. Int J Fatigue 2010;32:1428-47.

[17] Chan KS, Lee YD. Effects of Deformation-Induced constraint on high-cycle fatigue in Ti alloys with a duplex microstructure. Metall Mater Trans A 2008;39:1665-75.
[18] Chai G. The formation of subsurface non-defect fatigue crack origins. Int J Fatigue 2006;28:1533-9.

[19] Chai G, Zhou N, Ciurea S, Andersson M, Peng RL. Local plasticity exhaustion in a very high cycle fatigue regime. Scripta Mater 2012;66:769-72.

[20] Edwards P, Ramulu M. Effect of build direction on the fracture toughness and fatigue crack growth in selective laser melted Ti-6Al-4 V. Fatigue Fract Eng Mater Struct 2015;38:1228-36.

[21] Zuo JH, Wang ZG, Han EH. Effect of microstructure on ultra-high cycle fatigue behavior of Ti-6Al-4V. Mater Sci Eng A 2008;473:147-52.

[22] Furuya Y, Takeuchi E. Gigacycle fatigue properties of Ti-6Al-4V alloy under tensile mean stress. Mater Sci Eng A 2014;598:135-40.

[23] Takeuchi E, Furuya Y, Nagashima N, Matsuoka S. The effect of frequency on the giga-cycle fatigue properties of a Ti-6Al-4V alloy. Fatigue Fract Eng Mater Struct 2008;31:599-605.

[24] Takeuchi E, Furuya Y, Nagashima N, Matsuoka S. Effect of stress ratio on gigacycle fatigue properties for Ti-6Al-4V Alloy. Tetsu-to-Hagane 2010;96:36-41.

[25] Morrissey R, Nicholas T. Fatigue strength of Ti-6Al-4V at very long lives. Int J Fatigue 2005;27:1608-12.

[26] Morrissey R, Nicholas T. Staircase testing of a titanium alloy in the gigacycle regime. Int J Fatigue 2006;28:1577-82.

[27] Oguma H, Nakamura T. The effect of microstructure on very high cycle fatigue properties in Ti-6Al-4V. Scripta Mater 2010;63:32-4.

[28] Oguma H, Nakamura T. Fatigue crack propagation properties of Ti-6Al-4V in vacuum environments. Int J Fatigue 2013;50:89-93.

[29] Tokaji K, Kariya H. Mean stress dependence of fatigue strength and subsurface crack initiation in Ti-15Mo-5Zr-3Al alloy. Mater Sci Eng A 2000;281:268-74.

[30] Szczepanski CJ, Jha SK, Larsen JM, Jones JW. Microstructural influences on very-high-cycle fatigue-crack initiation in Ti-6246. Metall Mater Trans A 2008;39:2841-51.

[31] Matsunaga H, Sun C, Hong Y, Murakami Y. Dominant factors for very-highcycle fatigue of high-strength steels and a new design method for components. Fatigue Fract Eng Mater Struct 2015;38:1274-84.

[32] Przybyla CP, McDowell DL. Microstructure-sensitive extreme-value probabilities of high-cycle fatigue for surface vs. subsurface crack formation in duplex Ti-6Al-4V. Acta Mater 2012;60:293-305.

[33] Li W, Yuan H, Sun Z, Zhang Z. Surface vs. interior failure behaviors in a structural steel under gigacycle fatigue: failure analysis and life prediction. Int J Fatigue 2014;64:42-53.

[34] Bantounas I, Dye D, Lindley TC. The effect of grain orientation on fracture morphology during high-cycle fatigue of Ti-6Al-4V. Acta Mater 2009;57:3584-95.

[35] Bantounas I, Dye D, Lindley TC. The role of microtexture on the faceted fracture morphology in Ti-6Al-4V subjected to high-cycle fatigue. Acta Mater 2010;58:3908-18.

[36] Bantounas I, Lindley TC, Rugg D, Dye D. Effect of microtexture on fatigue cracking in Ti-6Al-4V. Acta Mater 2007;55:5655-65.

[37] Bridier F, Villechaise P, Mendez J. Analysis of the different slip systems activated by tension in a $\alpha / \beta$ titanium alloy in relation with local crystallographic orientation. Acta Mater 2005;53:555-67.

[38] Biavant KL, Pommier S, Prioul C. Local texture and fatigue initiation in a Ti-6Al4V titanium alloy. Fatigue Fract Eng Mater Struct. 2002;25:527-45.

[39] Chandran KSR, Jha SK. Duality of the S-N fatigue curve caused by competing failure modes in a titanium alloy and the role of Poisson defect statistics. Acta Mater 2005;53:1867-81.

[40] Chandran KSR, Chang P, Cashman GT. Competing failure modes and complex S-N curves in fatigue of structural materials. Int J Fatigue 2010;32:482-91.

[41] Freudenthal AM. The statistical aspect of fatigue of materials. Proc Roy Soc A: Math Phys Eng Sci 1946;187:416-29.

[42] Berto F, Campagnolo A, Lazzarin P. Fatigue strength of severely notched specimens made of Ti-6Al-4V under multiaxial loading. Fatigue Fract Eng Mater Struct 2015;38:503-17.

[43] Léopold G, Nadot Y, Billaudeau T, Mendez J. Influence of artificial and casting defects on fatigue strength of moulded components in Ti-6Al-4V alloy. Fatigue Fract Eng Mater Struct 2015;38:1026-41. 